\title{
The Roles of Oxide Growth and Sub-Surface Facets in Oxygen Evolution Activity of Iridium and Its Impact on Electrolysis
}

\author{
Shaun M. Alia, ${ }^{1,=, *, z}$ Mai-Anh Ha, ${ }^{2,}=$ Grace C. Anderson, ${ }^{1}$ Chilan Ngo, ${ }^{3}$ \\ Svitlana Pylypenko, $\oplus^{3, *}$ and Ross E. Larsen ${ }^{2}$ \\ ${ }^{1}$ Chemistry and Nanoscience Center, National Renewable Energy Laboratory, Golden, Colorado 80401, USA \\ ${ }^{2}$ Computational Science Center, National Renewable Energy Laboratory, Parkway, Golden, Colorado 80401, USA \\ ${ }^{3}$ Department of Chemistry and Geochemistry, Colorado School of Mines, Golden, Colorado 80401, USA
}

\begin{abstract}
This paper combines density functional theory calculations and electrochemical testing to study activity differences among iridium (Ir) surfaces in the oxygen evolution reaction. Ir metal/hydroxide is significantly more active than Ir oxide, which may be due to oxide skins at the surface weakening O-binding relative to pure metal or oxide surfaces. Here we report a disparity in activity between Ir and Ir oxide in half-cells not observed in single-cells. Extended operation at elevated temperature and potential were found to result in oxide growth, limiting how surface differences affect electrolyzer performance. Comparisons of half- and single-cell testing were used to assess how well rotating disk electrode testing predicts membrane electrode assembly performance and durability. Although oxygen evolution activities in half-cells can translate to single-cells, standard rotating disk electrode test procedures can exaggerate the activity benefit of a metal/hydroxide surface relative to membrane electrode assembly performance under typical operating conditions; it also appears that a half-cell test cannot reasonably accelerate activity loss from continual operation. While a variety of novel catalyst approaches, including alloying, faceting, morphology, and supports can improve oxygen evolution kinetics, these results suggest that Ir surfaces at different oxide states may struggle to improve performance at the device level.

(C) The Author(s) 2019. Published by ECS. This is an open access article distributed under the terms of the Creative Commons Attribution Non-Commercial No Derivatives 4.0 License (CC BY-NC-ND, http://creativecommons.org/licenses/by-nc-nd/4.0/), which permits non-commercial reuse, distribution, and reproduction in any medium, provided the original work is not changed in any way and is properly cited. For permission for commercial reuse, please email: oa@electrochem.org. [DOI: 10.1149/2.0771915jes]
\end{abstract}

(cc) BY-NC-ND

Manuscript submitted August 2, 2019; revised manuscript received October 24, 2019. Published November 20, 2019. This was Paper 1441 presented at the Dallas, Texas, Meeting of the Society, May 26-May 30, 2019.

Hydrogen as an intermediate accounts for $2 \%$ of U.S. energy, contributing to ammonia production in agriculture and fuel upgrading in transportation. ${ }^{1}$ Due to the high cost of retail electricity used in low temperature electrolysis, industrial hydrogen is primarily produced by steam methane reformation. As the grid penetration of low-cost, intermittent, renewable power sources increases, electrochemical water splitting will be needed to produce hydrogen for storage and to offload to other applications. To become cost competitive, electrolysis needs to be coupled directly with low-cost renewables and to minimize the higher capital cost at lower capacity. ${ }^{1,2}$ While multiple components affect capital cost (membrane, transport layers, balance), catalyst loading reductions (platinum group metals) from several milligrams per square centimeter to tenths of milligrams per square centimeter are critical to reach hydrogen cost targets. ${ }^{3}$ Catalyst development, therefore, will become critical in the future to evaluate and improve electrolyzer performance and durability, and to grow the electrolysis market share.

Catalysis efforts in low temperature, proton exchange membrane (PEM)-based electrolysis tend to focus on the oxygen evolution reaction (OER) since it is 5-6 orders of magnitude kinetically slower than hydrogen evolution. ${ }^{3}$ Iridium (Ir) catalysts are also typically used due to a balance in performance (higher than platinum, Pt) and stability (higher than ruthenium, Ru). ${ }^{4-6}$ Recent efforts have addressed a range of electrolysis-related topics, including: establishing baselines in rotating disk electrodes (RDEs) ${ }^{7}$ and membrane electrode assemblies (MEAs); establishing relative stabilities; ${ }^{5,6}$ assigning performances for different surfaces, ${ }^{8,9}$ alloys, ${ }^{10-15}$ morphologies $;{ }^{16-18}$ and using these differences to improve upon Ir OER activity. Throughout these advancements, however, a clear understanding of how Ir near-surface composition and oxides influence activity observations and how they translate to MEA performance and durability has not been developed.

In addition to electrolysis, other experiments use oxides supported on metal ${ }^{19,20}$ (denoted oxide/metal) to tune the physicochemical or catalytic properties of materials. This layering of oxide/metal is used in a variety of applications, including: unique metal oxidation states from

\footnotetext{
$=$ These authors contributed equally to this work

* Electrochemical Society Member.

${ }^{\text {z}}$ E-mail: shaun.alia@nrel.gov
}

$\mathrm{IrO}_{2} / \mathrm{Ir}$ to produce electrochomic properties,${ }^{21,22}$ favorable NO adsorption of $\mathrm{FeO} / \mathrm{Ag},{ }^{23} \mathrm{CO}$ oxidation on $\mathrm{FeO} / \mathrm{Pt},{ }^{24} \mathrm{NiO} / \mathrm{Au}$; ${ }^{25}$ enhanced activity for methanol conversion on $\mathrm{CeO}_{\mathrm{x}} / \mathrm{Cu},{ }^{26}$ and formaldehyde production on $\mathrm{VO} / \mathrm{Rh}(111){ }^{27}$ Hence, there is a clear need to understand the properties of oxides supported on metal beyond catalyst design.

In this paper, we combine plane-wave density functional theory (PW-DFT) calculations of oxygen binding to different $\mathrm{Ir}$ and $\mathrm{IrO}_{2}$ facets with RDE and MEA testing to understand the activity differences between Ir surfaces and how these differences affect electrolysis performance. The results suggest that oxide skins forming at the surface of Ir metal/hydroxide may lead to weakened $\mathrm{O}$ binding and improved OER activity compared to bulk rutile Ir oxide. The formation of thin oxide layers at the surface may lead to one measured activity at the outset of operation that slowly changes over time due to the elevated temperature, high potential, and extended operation encountered during MEA operation. As one expects, oxides continue to grow during operation so that activity improvements from less-oxidized Ir surfaces do not translate to MEAs. In the following, we detail the combination of modeling and electrochemical characterization that leads to the aforementioned conclusions. These results have implications for catalyst design and development, how different Ir surfaces are used as baselines interchangeably, and how RDE improvements are used to infer MEA benefits. These findings also highlight the importance of understanding the growth and (in)stability of oxide skins at metal surfaces. Such considerations go beyond electrolysis applications, with relevance broadly to electrochemical processes and catalytic applications where a passivated metal (oxide supported on a metal) exhibits desirable properties.

\section{Experimental}

RDE working electrodes were coated to a loading of $17.8 \mu \mathrm{g}_{\mathrm{Ir}, \mathrm{Ru}} \mathrm{cm}^{-2}$ by previously established protocols. ${ }^{7} \mathrm{RDE}$ inks contained $3.5 \mathrm{mg}$ Ir in $7.6 \mathrm{ml}$ of water and $2.4 \mathrm{ml}$ of isopropanol. Inks were iced for $5 \mathrm{~min}$ prior to adding Nafion ionomer $(40 \mu \mathrm{l}$, $5 \mathrm{wt} \%$ ), then horn sonicated for $30 \mathrm{~s}$, bath sonicated for $20 \mathrm{~min}$, and horn sonicated for $30 \mathrm{~s}$ in ice. Following sonication, $10 \mu \mathrm{l}$ of ink were pipetted onto gold $(\mathrm{Au})$ working electrodes (Pine Instrument Company, AFE5T050AU) inverted on a modulate speed rotator (Pine 
Instrument Company, AFMSRCE). The working electrodes were rotated at $100 \mathrm{rpm}$ during the coating process; the rotation speed was then increased to $700 \mathrm{rpm}$ while the electrodes dried for $20 \mathrm{~min}$. The coating process resulted in working electrodes coated to a loading of $17.8 \mu \mathrm{g}_{\mathrm{Ir}, \mathrm{Ru}} \mathrm{cm}^{-2}$ and an ionomer content of $0.1 \mu \mathrm{g}_{\text {Nafion }} \mathrm{mg}_{\mathrm{Ir}, \mathrm{Ru}}{ }^{-1}$.

Testing was completed in a three-electrode cell, using the coated Au working electrodes (Pine Instrument Company, AFE5T050AU), a Au mesh counter, and a reversible hydrogen (RHE) reference. The counter was connected to the main cell by a Vycor frit and the reference to the main cell by a Luggin capillary. Electrochemical testing was completed in a $0.1 \mathrm{M}$ perchloric acid electrolyte, using an Autolab PGSTAT302N (EcoChemie, Metrohm) and a modulated speed rotator. Catalysts were electrochemically conditioned for 50 cycles in the potential range $1.2-1.8 \mathrm{~V}$ vs. RHE at $100 \mathrm{mV} \mathrm{s}^{-1}$ and $2500 \mathrm{rpm}$. Activities were then determined at $1.55 \mathrm{~V}$ vs. RHE during linear sweep voltammograms in the potential range $1.2-1.65 \mathrm{~V}$ vs. RHE at $20 \mathrm{mV} \mathrm{s}^{-1}$ and $2500 \mathrm{rpm}$; full linear sweep voltammograms were also taken at $20 \mathrm{mV} \mathrm{s}^{-1}$ and $2500 \mathrm{rpm}$ in the potential range $1.2-2.0 \mathrm{~V}$ vs. RHE. Internal resistance (iR) values $(22-25 \Omega)$ were taken using a built-in current interrupter at $1.6 \mathrm{~V}$ vs. RHE and iR was corrected for by the potentiostat during activity measurements to account for resistance between the reference and working electrodes. During RDE testing, an upper potential limit of $1.8 \mathrm{~V}$ was used for conditioning and $1.65 \mathrm{~V}$ was used for evaluating kinetic activities. An upper potential limit of $1.65 \mathrm{~V}$ was used when evaluating kinetics since data at higher potential included transport and the lower current range (resistor) allowed for data accuracy at low current density with internal resistance correction accounted for during testing (avoided potential correction inaccuracies during data processing).

Electrochemical surface areas (ECAs) and site-specific activities were determined using mercury underpotential deposition, from the charge associated with the adsorption of a mercury monolayer. ${ }^{28,29}$ ECAs were determined during $20 \mathrm{mV} \mathrm{s}^{-1}$ cyclic voltammograms in the potential range $0.025-0.55 \mathrm{~V}$ vs RHE. Measurements assumed a Coulombic charge of $138.6 \mu \mathrm{C} \mathrm{cm}_{\mathrm{Ir}}{ }^{-2}$, which on a polished Ir electrode produced a roughness factor of 1.3 .

Catalyst durability was evaluated by $13.5 \mathrm{~h}$ potential holds at $1.6 \mathrm{~V}$ (oxide growth) and $2 \mathrm{~V}$ (dissolution). Potential cycling was generally not used since it did not accelerate either loss mechanism. iR corrections were not applied to durability since the uncorrected potential may be more representative of that at the catalyst layer and the potential correction had a dramatic impact on dissolution and activity loss rates. Transmission electron microscopy (TEM) images of Ir metal/hydroxide were completed on a Philips CM200 for the material as-received and after durability testing at $1.6 \mathrm{~V}$ vs. RHE. Inductively coupled plasma mass spectrometry (ICP-MS) was completed on RDE electrolytes after conditioning and durability testing to evaluate $\mathrm{Ir} / \mathrm{Ru}$ dissolution. ICP-MS values were calibrated to a blank, an internal standard, and three Ir standards at concentrations of 2, 20, and $200 \mathrm{ppb}$ matrix matched to the electrolyte. Electrolytes were analyzed three times at a dwell time of $0.15 \mathrm{~s}$ and a reproducibility within a $2 \%$ deviation. Percentage dissolution was determined by completing the mass balance from the initial catalyst mass on the working electrode and the mass dissolved into the electrolyte (concentration determined in ICP-MS, volume known).

Test factors that could affect the RDE durability evaluations of OER catalysts were a concern, including bubble formation or mechanical stress (rotating electrode) resulting in catalyst delamination, and corrosion/oxidation of the $\mathrm{Au}$ working electrode. Catalyst detachment was previously excluded as the primary cause of loss since negligible loss occurred at lower potential with similar gas generation rates (hydrogen peroxide oxidation). ${ }^{3}$ To evaluate the working electrode dissolution, the Au concentration was evaluated with ICP-MS for electrolyte aliquots taken following durability testing (1.6 or $2 \mathrm{~V}$ holds). In all cases, the Au concentration was 2-10 ppt, close to or slightly above the ICP-MS detection limit (IDL, 1$5 \mathrm{ppt}$ ). Oxidation of the $\mathrm{Au}$ working electrode was also not found in the form of large capacitance changes associated with extensive ox- ide growth or internal resistance correction increases associated with lower electrode conductivity. Aspects of the RDE process, including efforts to uniformly cast catalyst layers and include ionomer may somewhat mitigate these issues, by limiting access to the substrate (Au dissolution effect), linking catalyst sites (Au oxidation effect), or improving catalyst layer resistance to mechanical stress (catalyst detachment). ${ }^{7}$ These factors were generally seen as minor contributors to catalyst durability since no performance loss was observed on Ir oxide and losses due to Ir (metal/hydroxide) oxidation were reversible.

MEAs were sprayed as catalyst-coated membranes on Nafion 117 using a Sonotek spray system equipped with an Accumist spray nozzle. For MEA anodes, Ir/Ru inks were prepared by adding $75 \mathrm{mg}$ of catalyst (Ir/Ru basis) to $15.5 \mathrm{ml}$ of water and $11.9 \mathrm{ml}$ of n-propanol. For MEA cathodes, Pt inks contained Pt supported on high surface area carbon (Tanaka Kikinzoku Kogyo TEC10E50E) and were prepared by adding $64 \mathrm{mg}$ of catalyst (total mass basis) to $16.6 \mathrm{ml}$ of water and $12.7 \mathrm{ml}$ of n-propanol. After $5 \mathrm{~min}$ of icing, Nafion ionomer was added ( $20 \mathrm{wt} \%, 98 \mu \mathrm{l}$ to the $\mathrm{Ir} / \mathrm{Ru}$ ink, $76 \mu \mathrm{l}$ to the Pt ink) and the inks were horn sonicated for $30 \mathrm{~s}$, bath sonicated for $20 \mathrm{~min}$, and horn sonicated for $30 \mathrm{~s}$. The inks were sprayed onto the membrane vacuumed to a hot plate at $80^{\circ} \mathrm{C}$ at a rate of $0.2 \mathrm{ml} \mathrm{min}{ }^{-1}$, to a loading of $0.1 \mathrm{mg} \mathrm{cm}^{-2}$ at the anode ( $\mathrm{Ir} / \mathrm{Ru}$ basis) and cathode (Pt basis), with ionomer contents of $0.267 \mathrm{mg}_{\text {Nafion }} \mathrm{mg}_{\mathrm{Ir}, \mathrm{Ru}}{ }^{-1}$ (anode) and $0.452 \mu \mathrm{g}_{\text {Nafion }} \mathrm{mg}_{\text {Carbon }}{ }^{-1}$ (cathode). Loadings were verified by X-ray fluorescence (XRF) with a XDV-SDD with the average of four measurements at a 30 s exposure time.

MEAs were assembled using aluminum end plates (Fuel Cell Technologies), a carbon flow field (Fuel Cell Technologies) and porous transport layer (Toray, $5 \mathrm{wt} \%$ polytetrafluoroethylene) at the cathode, and a platinized titanium flow field and porous transport layer (Giner, Inc.) at the anode. Single-cell operation was completed with a $0.3 \mathrm{~L} \mathrm{~min}^{-1}$ at the anode and dry on the cathode with no back pressure, at $80^{\circ} \mathrm{C}$ unless specified otherwise. Typical conditioning procedures included a: 5 A hold for $1 \mathrm{~h}$; 25 A hold for $1 \mathrm{~h} ; 2 \mathrm{~V}$ hold for $1 \mathrm{~h} ; 1.7 \mathrm{~V}$ hold for $2 \mathrm{~h}$; and $2 \mathrm{~V}$ hold for $1 \mathrm{~h}$. Polarization curves were then taken cathodically, then anodically at various potentials/currents, for $5 \mathrm{~min}$ at each point. Cyclic voltammograms were collected in the potential range $0.025-1.3 \mathrm{~V}$ and $0.025-1.4 \mathrm{~V}$ at $50 \mathrm{mV} \mathrm{s}^{-1}$ and impedance data were collected at a variety of currents. Typical conditioning and performance evaluation protocols were avoided during Ir metal/hydroxide oxidation studies to avoid prolonged exposure to elevated temperature $\left(80^{\circ} \mathrm{C}\right)$ and potential $(2 \mathrm{~V})$. Durability tests for the catalyst survey were completed by square waves, $30 \mathrm{~s}$ at $2 \mathrm{~V}$ followed by $30 \mathrm{~s}$ at $1.45 \mathrm{~V}$.

All PW-DFT calculations were performed using the Vienna AbInitio Simulation Package (VASP 5.4) ${ }^{30}$ with the most recent projector augmented wave (PAW) $)^{31}$ pseudopotentials available. The spinunrestricted calculations utilized the PBEsol functional, a variant of the PBE functional parametrized for solid-state systems. ${ }^{32}$ The optimized lattice constants for $\operatorname{Ir}(\mathrm{a}=3.8394 \AA)$ and $\operatorname{IrO}_{2}(\mathrm{a}=4.5035 \AA)$ compared well to experiment, with Ir matching experiment and $\mathrm{IrO}_{2}$ optimizing to a slight increase of $0.3 \%$ from experiment. ${ }^{33}$ For all calculations, the plane wave basis sets were expanded to $400 \mathrm{eV}$ with stringent convergence criteria of $10^{-5}\left(10^{-6}\right) \mathrm{eV}$ for geometric (electronic) relaxation. Oxygen adsorption energies were determined by the equation: $E_{\mathrm{O}}=E_{\text {surf }+\mathrm{O}}-\mathrm{E}_{\text {surf }}-\frac{1}{2} \mathrm{E}_{\mathrm{O} 2}$, where $\mathrm{E}_{\text {surf }+\mathrm{O}}$ is the total energy of the surface with adsorbed oxygen, $E_{\text {surf }}$ is the total energy of the clean surface, and $\mathrm{E}_{\mathrm{O} 2}$ is the total energy of diatomic oxygen (calculated using the PBE functional only due to diatomic oxygen's gaseous phase). Energetic changes from the fixed mixed $\mathrm{Ir}-\mathrm{IrO}_{2}$ surfaces were evaluated as $\Delta E_{\text {fixed-rel,surf }}=E_{\text {fixed,surf }}-E_{\text {rel,surf }}$, where $E_{\text {fixed,surf }}$ is the total energy of the fixed surface and $E_{\text {rel,surf }}$ is the total energy of the relaxed surface. Bader charge algorithm was used to assess charge transfer between the surface and adsorbed oxygen. ${ }^{34}$ PDOS plots provided detailed bonding information between orbitals, the broadness and intensity of orbital overlap demonstrating adsorption strength and electronic acceptor/donor relationship between the surface and adsorbed species. ${ }^{35}$ We highlight the orbital overlap between orbitals 

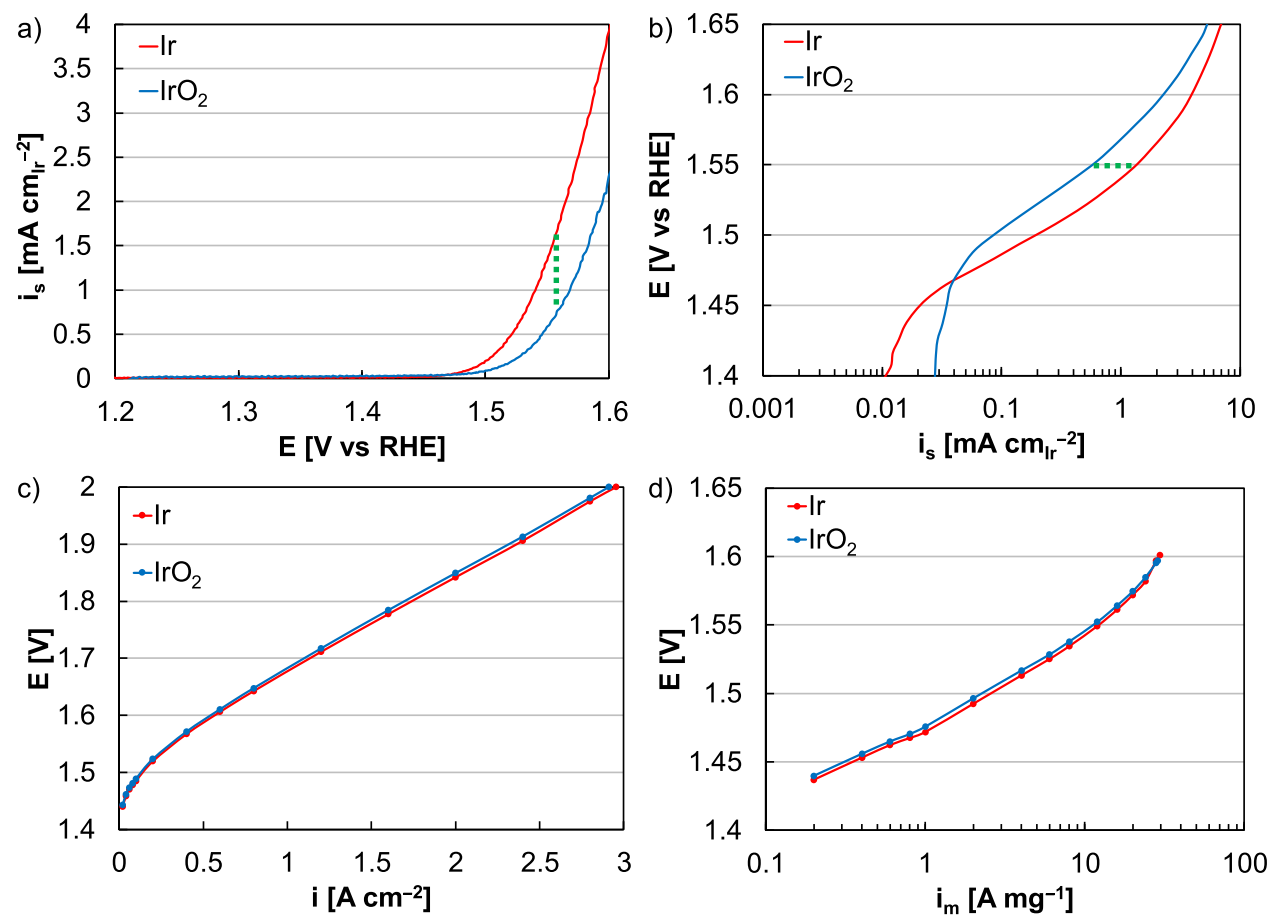

Figure 1. Comparison of Ir (metal/hydroxide, red) and Ir oxide (blue) site-specific activities in RDE half-cells, presented as (a) linear sweep voltammograms and (b) Tafel plots to focus on the kinetic region. The performance gap between Ir (metal/hydroxide) and Ir oxide (blue) in RDE half-cells was highlighted by a dashed green line. Comparison of Ir (metal/hydroxide, red) and Ir oxide (blue) performance in MEA single-cells, presented as (c) polarization curves (electrode area basis) and (d) Tafel plots to focus on the kinetic region (Ir/anode mass basis).

that demonstrate the strength of bonding between surface iridium and adsorbed oxygen. For detailed information of the surfaces and their associated k-point mesh, see SI.

\section{Results and Discussion}

Oxygen evolution activity of surfaces.-When comparing the OER activity of Ir surfaces, a large gap is often observed in RDE testing where metal/hydroxide is found to be more active than rutile or mixed oxides (green dashed line, Figures 1a, 1b). While standard commercial nanoparticle baselines have similar surface areas (Johnson Matthey Ir $27.8 \mathrm{~m}^{2} \mathrm{~g}_{\mathrm{Ir}}{ }^{-1}$, Alfa Aesar Ir oxide $\left.28.8 \mathrm{~m}^{2} \mathrm{~g}_{\mathrm{Ir}}{ }^{-1}\right)$, Ir is twice as active for OER within the kinetic region $(\leq 1.55 \mathrm{~V})$ on a mass- and site-normalized basis. ${ }^{3}$ Although Ir is more active than Ir oxide in RDE, this gap is not observed in MEAs where the performances are similar in the kinetic and high current density regions (Figures 1c, 1d). ${ }^{36}$ In this study, plane wave density-functional theory (PW-DFT) calculations and catalyst testing (half- and single-cells) are used to resolve this discrepancy and elucidate why different Ir surfaces are more or less active for OER. Throughout this study, Johnson Matthey Ir is referred to as metal/hydroxide since the X-ray diffraction (XRD) patterns indicated the presence of Ir metal (Supporting Information, SI Figure S.1) and ICP-MS suggested largely metal composition (99.3 wt\% Ir, $100 \mathrm{wt} \%$ theoretical, SI Table S.1); conversely, Alfa Aesar Ir oxide is referred to as rutile since XRD patterns indicated the presence of rutile Ir oxide (SI Figure S.1) and ICP-MS suggested a largely IrO2 composition (84.6 wt\% Ir, $85.7 \mathrm{wt} \%$ theoretical, SI Table S.1).

To understand differences between ex- and in-situ activity evaluations, factors influencing oxide formation/growth were evaluated. In RDE, standard conditioning protocols included 50 cycles in the potential range $1.2-1.8 \mathrm{~V}$ at $100 \mathrm{mV} \mathrm{s}^{-1}$, totaling $10 \mathrm{~min}$ at room temperature and potentials greater than Ir redox. Following this step, activity was determined with a linear sweep voltammogram, $20 \mathrm{mV} \mathrm{s}^{-1}$ in the potential range 1.2-1.65 V (kinetic focus). For MEAs, conditioning included a hold at $0.2 \mathrm{~A} \mathrm{~cm}^{-2}$ for $1 \mathrm{~h}$, a hold at $1 \mathrm{~A} \mathrm{~cm}^{-2}$ for
$1 \mathrm{~h}$, a hold at $2 \mathrm{~V}$ for $0.5 \mathrm{~h}$, a hold at $1.7 \mathrm{~V}$ for $2 \mathrm{~h}$, and a hold at $2 \mathrm{~V}$ for $0.5 \mathrm{~h}$, totaling $5 \mathrm{~h}$ at $80^{\circ} \mathrm{C}$ and potentials greater than Ir redox. Following the conditioning step, performance was determined with anodic and cathodic polarization curves (galvanostatic) with a $5 \mathrm{~min}$ step duration. In this way, significant differences were noted between RDE and MEA conditioning with respect to: temperature, room (RDE) or $80^{\circ} \mathrm{C}$ (MEA); experiment duration, $10 \mathrm{~min}(\mathrm{RDE})$ or $5 \mathrm{~h}$ (MEA); and potential, up to $1.8 \mathrm{~V}$ (RDE) or $2 \mathrm{~V}$ (MEA). Differences between these conditioning protocols may preserve near-surface Ir (metal) with a surface oxide or grow a thicker oxide layer, resulting in differences with regards to intermediate binding and OER activity. In effect, the conditions for MEAs change the material being tested such that activities determined with an RDE protocol could be effectively unrelated to in operando MEA results.

In order to study the effect of conditioning duration on oxide growth and RDE activity, Ir metal/hydroxide was exposed to moderate oxidative potential for longer periods of time. During a $13.5 \mathrm{~h}$ hold at $1.6 \mathrm{~V}$, the OER activity (mass- and site-specific) of Ir gradually decreased and approached Ir oxide (Figure 2a, SI Table S.2). Performance loss was attributed to oxide growth since neither Ir dissolution (Figure 2d, SI Table S.3) nor aggregation (particle growth, Figures 2e-2f, SI Figure S.2) were found. Previous efforts also found a minimal decrease in surface area (mercury underpotential deposition) when Ir (metal/hydroxide) was exposed to moderate potentials $(1.4-1.6 \mathrm{~V})$ for extended periods of time $(13.5 \mathrm{~h}) .^{7}$ Oxidation was confirmed with cyclic voltammograms, where the loss of hydrogen underpotential deposition features indicated the loss of a metallic surface (Figure 2b). The capacitance, however, did not grow suggesting that oxidation occurred at the nearsurface but not throughout the nanoparticle core. There was also a gap between the time required to lose metallic features (Figure $2 b$ ) and lose OER activity (Figure 2a), and some growth of the oxide layer may be needed to induce lower performance. In these experiments, the conditions needed to grow thick oxide layers and impact cyclic voltammograms and OER activity was significantly longer and at higher potentials than single-crystal Ir surfaces (single scan, low potential) and smaller nanoparticles (cycled at low potential). ${ }^{6,37}$ Although 

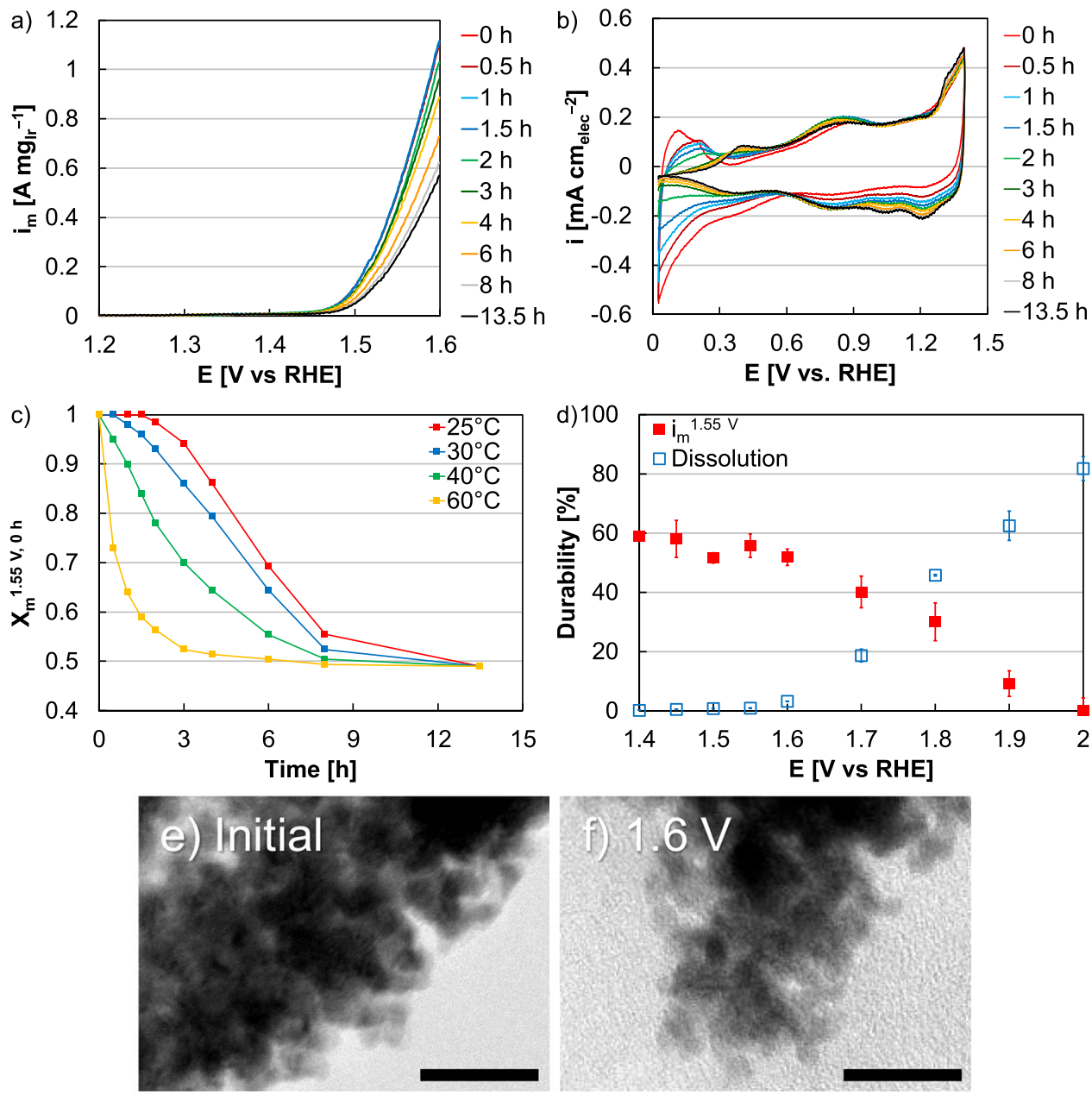

Figure 2. (a) Linear sweep (b) and cyclic voltammograms Ir (metal/hydroxide) nanoparticles taken periodically during a $1.6 \mathrm{~V}$ hold, with the time specified in the subfigure legends. (c) Loss of initial OER activity (fraction basis) for $\operatorname{Ir}$ (metal/hydroxide) at $25^{\circ} \mathrm{C}$ (red), $30^{\circ} \mathrm{C} \mathrm{(blue),} 40^{\circ} \mathrm{C}$ (green), and $60^{\circ} \mathrm{C}$ (yellow) as a function of time during a $1.6 \mathrm{~V}$ hold. (d) Durability results, in terms of mass activity retained (red) and catalyst mass lost to dissolution (blue) at various potential holds (13.5 h), specified on the x-axis. Microscopy of Ir (metal/hydroxide) nanoparticles (e) prior to and following a 13.5 hold at (f) $1.6 \mathrm{~V}$. Scale bars are equivalent to $10 \mathrm{~nm}$. OER activities were corrected for internal resistance, in subfigures (a), (c), and (d).

significant oxide growth has been found on Ir facets (particularly $\operatorname{Ir}(111))$ with exposure to potentials below Ir redox, changes associated with oxide growth (hydrogen underpotential deposition, capacitance growth, OER activity loss) did not occur on the commercial nanoparticles evaluated without exposure to moderate potential (above Ir redox) for extended periods of time. Differences between these systems may be due to differences in: facets; the susceptibility of single facets, thin films, and particles to grow thicker oxide layers; or near-surface oxide content based on facet/catalyst preparation.

Additionally, the effect of temperature on near-surface oxidation and OER activity was evaluated and higher temperature increased the rate of OER activity loss; while a $35 \%$ loss in mass OER activity required $7 \mathrm{~h}$ at $25^{\circ} \mathrm{C}$, it occurred in $4 \mathrm{~h}$ at $40^{\circ} \mathrm{C}$ and $1 \mathrm{~h}$ at $60^{\circ} \mathrm{C}$ (Figure 2c, SI Figures S.3, S.4). These experiments demonstrated that elevated temperature and extended operation resulted in lower OER activity. Faster oxide growth at higher temperature was generally seen as the cause of accelerated performance decreases; although the Ir dissolution rate and ECA loss increased at higher temperature, these losses were minor $(<4 \%$ ECA loss, $<5 \%$ dissolution, SI Figure S.5) compared to the activity decrease (50\%). This process, however, was reversible and the activity recoverable (SI Figures S.6), in keeping with other systems. ${ }^{21,22}$ The inverse of this process was also possible, where low potential $(0.4 \mathrm{~V})$ over extended periods of time reduced the Ir oxide near-surface and improved OER activity (SI Figure S.7).
Analogous experiments were completed in MEAs, using Ir and Ir oxide as the anode catalyst. MEAs were operated at $1.6 \mathrm{~V}$ at various temperatures for $13.5 \mathrm{~h}$ while periodically taking performance measurements (Figures 3a, 3b) and cyclic voltammograms (Figure 3c). Test conditions were chosen to avoid exposure to elevated temperature and potential and included bypassing conditioning protocols and accelerating performance measurements (linear sweep voltammograms to $1.7 \mathrm{~V}$ instead of polarization curves). For both Ir and Ir oxide, initial operation (up to $3 \mathrm{~h}$ ) improved performance and may have been due to contaminant removal, altering the catalyst layer, or altering the catalyst/ionomer/membrane interface. Following this period, several trends were observed (Figure 3a). First, at $25^{\circ} \mathrm{C}$ the Ir MEA produced double the mass activity of Ir oxide in the kinetic region, a similar activity gap to the one observed in half-cell tests. Second, Ir performance similarly declined over time and approached the performance of Ir oxide toward the end of the experiment, likely due to oxide growth on the electrode surface. Third, at higher temperatures the rate of Ir oxidation increased and the gap between Ir and Ir oxide performance decreased. The changes in OER performance strongly correlated to the shape of cyclic voltammograms, and a large shift was found between 30 and $40^{\circ} \mathrm{C}$ (Figures $3 \mathrm{c}, 3 \mathrm{~d}$ ). At $30^{\circ} \mathrm{C}$, Ir outperformed Ir oxide kinetically by $50 \%$ and hydrogen underpotential deposition features were found; by $40^{\circ} \mathrm{C}$, however, the performance benefit had dropped to $10 \%$ and the hydrogen underpotential deposition peaks sharply decreased. At all temperatures, Ir performance approached Ir oxide by the end of 

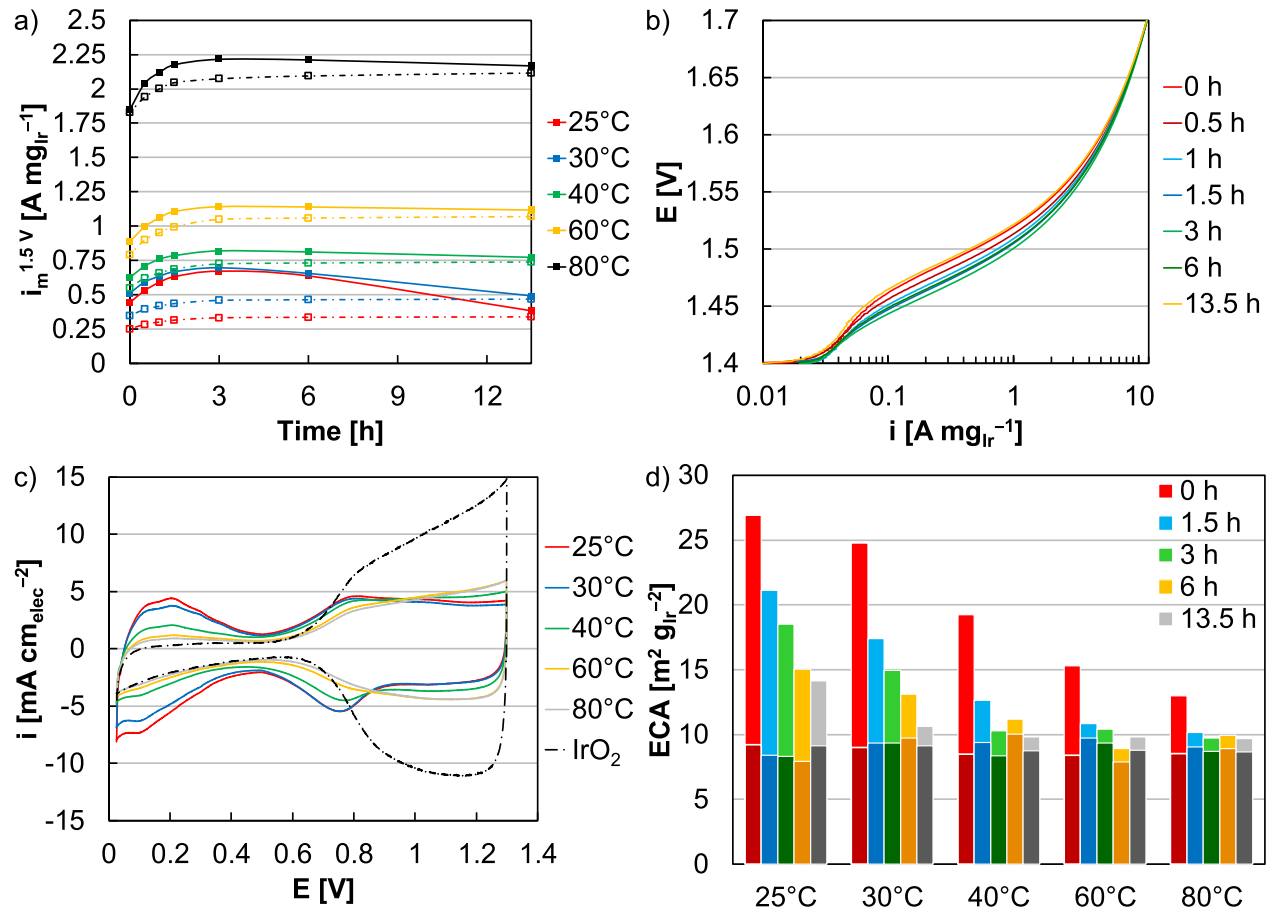

Figure 3. (a) MEA performance in the kinetic region (1.5 V) for $\operatorname{Ir}$ (solid lines) and Ir oxide (dashed lines) as a function of temperature (specified in the subfigure legend) and time (specified on the $\mathrm{x}$-axis). (b) Ir-MEA performance at $25^{\circ} \mathrm{C}$ during a $1.6 \mathrm{~V}$ hold, with time specified in the subfigure legend. (c) Cyclic voltammograms of Ir-MEAs (solid lines) at various temperatures, specified in the subfigure legend. A cyclic voltammogram of an Ir oxide-MEA (dashed line) at $80^{\circ} \mathrm{C}$ was provided as a reference. (d) ECAs of Ir-MEAs during a $1.6 \mathrm{~V}$ hold, as a function of operating temperature (specified on the $\mathrm{x}$-axis) and time (specified in the subfigure legend). ECA calculations were completed for the charge associated with hydrogen underpotential deposition (lighter colors) and capacitance (darker colors). More information is available in SI (SI Figure S.8, SI Table S.4).

the experiment (13.5 h, Figure 3a). Since MEA conditioning occurs at elevated temperature and over a longer period of time $(5 \mathrm{~h})$, oxide growth minimized the activity gaps for different Ir surfaces found in RDE.

To explain this process, where Ir activity changed as the surface transitioned from metal to a surface oxide to fully oxidized (rutile, $\mathrm{IrO}_{2}$ ), PW-DFT calculations were performed, utilizing oxygen adsorption as a gauge of a surface's catalytic potential. It is well known that intermediate oxygen adsorption energetics often correlates to high activity and considerable work has been done for the reverse reaction of oxygen reduction. ${ }^{38,39}$ Yu et al. observed in their mechanistic study of oxygen reduction to form water on transition metal surfaces that oxygen binding energy correlated well with the rate determining step. Intermediate to weaker oxygen adsorption resulted in a rate determining step associated with the formation of water while stronger oxygen adsorption correlated to rate determining steps associated with the formation of other intermediates (e.g. $\mathrm{OH}$ or $\mathrm{OOH}$ ). Since a range of surfaces may be present, depending on synthesis conditions, such as temperature, pressure, substrate, and, in electrochemical environments, $\mathrm{pH}$ and potential, we examined multiple facets of iridium and iridium oxide. ${ }^{40-43}$

In particular, nanostructure surfaces often feature some percentage of all three facets typical of fcc metals e.g. (100), (110), and (111). ${ }^{40}$ For rutile $\mathrm{IrO}_{2}$, we limited our calculations to two facets, (110) and (001). The (110) facet is typically considered the more stable and less active facet as compared to (100), (101), and (001), where surface Ir atoms are under-coordinated and potentially more reactive toward oxygen-containing species. ${ }^{44,45}$ The (001) surface is also of interest because it possesses the most accessible surface iridium atoms; both (101) and (100), similar to (110), contain bridging oxygen atoms that can block adsorption. ${ }^{46}$ Thus, we chose to compare the $\mathrm{IrO}_{2}(110)$ facet, which contains surface $\mathrm{Ir}$ atoms that are 6-fold $\left(\operatorname{Ir}_{6 \mathrm{f}}\right)$ and 5-fold $\left(\mathrm{Ir}_{5 \mathrm{f}}\right)$ coordinated to $\mathrm{O}$ atoms, and the $\mathrm{IrO}_{2}(001)$ facet, whose surface $\mathrm{Ir}$ atoms are 4-fold $\left(\mathrm{Ir}_{4 \mathrm{f}}\right)$ coordinated to $\mathrm{O}$ atoms (see Figure 4 for visualization, SI Figures S.9-S.15 for greater detail). We found that oxygen adsorption differs greatly: in order of increasing oxygen binding strength, $\mathrm{IrO}_{2}(110)<\mathrm{Ir}(111)<\mathrm{IrO}_{2}(001)<\mathrm{Ir}(100)<$ $\mathrm{Ir}(110)$. All the surface Ir atoms in $\mathrm{IrO}_{2}(001)$ are under-coordinated compared to $\mathrm{IrO}_{2}$ (110), resulting in more charge transfer to the adsorbed oxygen and optimal overlap of the Ir's $5 \mathrm{~d}_{\mathrm{z} 2}$ and O's $2 \mathrm{p}_{\mathrm{z}}$ orbitals for stronger binding (see Figure 4 for projected density of states). On $\mathrm{IrO}_{2}$ (110), the weaker adsorption of oxygen may also arise due to the steric effects of neighboring, bridging oxygen (circa $3 \AA$ away). The $\mathrm{IrO}_{2}$ (110) surface is corrugated with bridging oxygens normal to the surface, which may block higher coverages of reaction intermediates as compared to the nearly flat $\mathrm{IrO}_{2}(001)$ surface, where all $\mathrm{Ir}$ atoms are under-coordinated and readily available for catalysis. We stress that the relative activity of iridium metal, however, will be higher than that of iridium oxide due to the higher surface area of available Ir sites.

We hypothesize that the brief increases in OER activity of $\mathrm{Ir}$ metal/hydroxide catalysts (Figure 3a) may be related to morphological changes at the onset of electrolysis. The geometric and electronic effects of alloying Pt are well known, resulting in weakened adsorption of key reaction intermediates and enabling these intermediates to potentially desorb and re-expose a catalytic site. ${ }^{40}$ Here, we will detail the catalytic effects of oxidizing the metal surface via a metal oxide skin: comparing the effects of the metal subsurface's facets e.g. (100), (110), and (111) and oxide skin thickness, 2-layers versus 4-layers. von Boehn et al. observed that formaldehyde production occurred on $\mathrm{VO} / \mathrm{Rh}(111)$, but was absent on $\mathrm{VO} / \mathrm{Rh}(110)$, suggesting the need to examine a range of sub-surface facets for what is nominally the same active surface, since the subsurface facet can determine selectivity. ${ }^{27}$ Özer et al. explored the facet-dependence of Ir (111) and Ir (110) during electrochemical activation-oxidation protocols, finding that Ir (110) exhibited higher initial activity than Ir (111) and maintained access to metallic Ir even after being fully oxidized, detectable via hydrogen underpotential desorption. ${ }^{37}$ Metal nanostructures are known to expose all three facets in some proportion..$^{40,47-49}$ Experimental surface science studies note that controlled introduction of oxygen can preferentially expose specific facets of rutile $\mathrm{IrO}_{2}$, often reaching a 


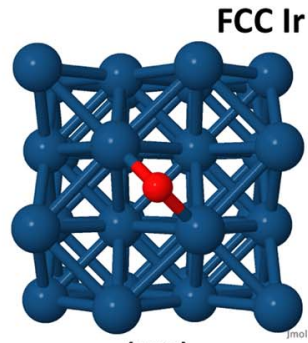

(100)

$E_{\mathrm{o}}(\mathrm{ev})=-1.89$

$\Delta Q_{0}(e)=-0.69$

CC Ir Metal: (100) versus (110) versus (111)

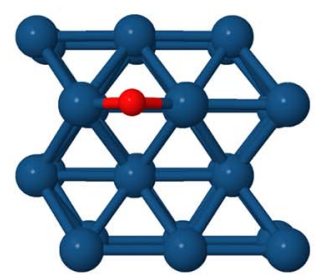

(110)

$E_{\mathrm{o}}(\mathrm{ev})=-2.33$

$\Delta Q_{0}(e)=-0.71$

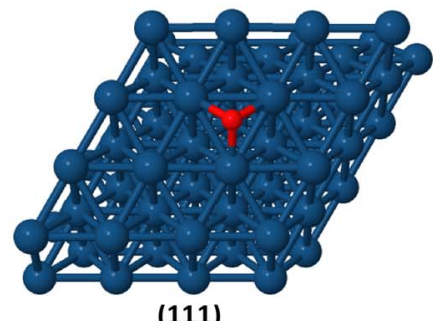

(111)

$E_{\mathrm{o}}(\mathrm{ev})=-1.55$

$\Delta Q_{0}(\mathrm{e})=-0.76$

Rutile $\mathrm{IrO}_{2}$ : (001) versus (110)

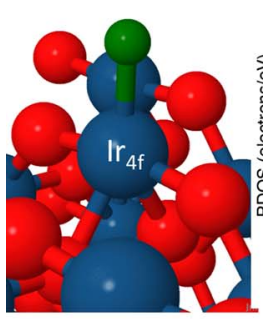

(001)

$\mathrm{E}_{\mathrm{o}}(\mathrm{ev})=-1.68$

$\Delta Q_{0}(e)=-0.85$

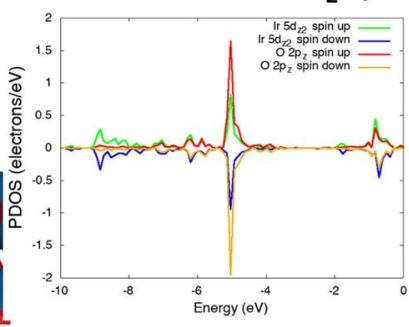

Optimal $02 p_{z}$

and Ir $5 d_{z 2}$ overlap

$\approx$ Stronger adsorption

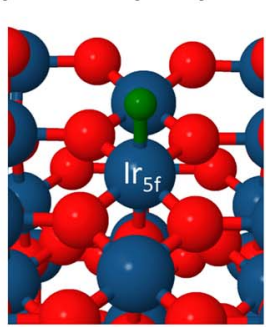

(110)

$\mathrm{E}_{\mathrm{O}}(\mathrm{ev})=-0.93$

$\Delta Q_{0}(e)=-0.70$

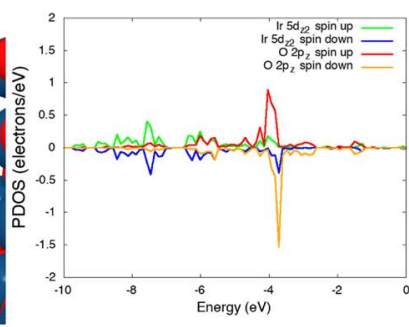

Less optimal $02 p_{z}$ and Ir $5 \mathrm{~d}_{\mathrm{z2}}$ overlap

$\approx$ Weaker adsorption

Figure 4. Global minima of oxygen bound to Ir metal (top) and rutile $\mathrm{IrO}_{2}$ (bottom). On $\mathrm{IrO}_{2}(001)$, oxygen adsorbs to a surface iridium coordinated to 4 oxygen atoms $\left(\mathrm{Ir}_{4 \mathrm{f}}\right)$; on $\mathrm{IrO}_{2}(110)$, oxygen adsorbs to a surface iridium coordinated to 5 oxygen atoms $\left(\mathrm{Ir}_{5 \mathrm{f}}\right)$. Projected density of states (PDOS) illustrate the bonding environment between adsorbed oxygen and the surface iridium on these two facets. Iridium atoms are shown in blue and oxygen in red with the adsorbed oxygen displayed in green on the $\mathrm{IrO}_{2}$ surfaces to distinguish it from the $\mathrm{IrO}_{2}$ surface's oxygens.

saturation of four oxide layers on the Ir metal surface. ${ }^{46,50}$ While, Zeng et al. theoretically explored various metal (nickel, cobalt, manganese) oxide and hydroxide skins on subsurfaces of Pt and Au (111) for alkaline hydrogen evolution, they did not pursue other subsurface facets or varying the skin's thickness, ${ }^{51}$ both of which are relevant to this study.

We focused on the under-coordinated $\mathrm{IrO}_{2}$ (001) facet, which bound the oxygen adsorbate stronger, in order to test whether one can tune adsorption strength via an Ir sub-layer. In Figure 5, we visualize the surfaces in their initial coordinates with a perfect oxide skin and following relaxation and adsorption of oxygen. Our interest in these surfaces is two-fold: evaluating the morphological changes of these surfaces and gauging the catalytic potential of these surfaces via oxygen adsorption energetics. Following surface relaxation, the oxide skin rearranges considerably, resulting in a profusion of nonequivalent adsorption sites. To achieve an unbiased sampling of possible adsorption sites, a uniform grid of 100 sites per surface was used for initial positions of oxygen atoms; these sites are then optimized to determine adsorption sites and energies. Due to the complexity of the $\mathrm{IrO}_{2}$ surfaces on $\mathrm{Ir}$, a full reaction profile considering all adsorbates on these surfaces is beyond the scope of this study but we anticipate that adsorption energies for all intermediates in the OER pro- cess would likely show changes as a function of facet and oxide skin formation.

Concomitant with the changes in Ir coordination and lattice compression or expansion, the $\mathrm{IrO}_{2}$ skin contains a large range of oxygen binding strengths (Table I, SI Tables S.5-S.7). ${ }^{52}$ All relevant equations and computing details are summarized in the experimental section; greater specificity may also be found in the SI. PW-DFT results show that bonding becomes more delocalized as compared to the pure oxide with a concomitant drop in charge transfer between $\operatorname{Ir}, \mathrm{O}$ atoms $(\Delta \mathrm{Q})$ : Ir atoms in the oxide skin, on average, range from +1.12 to $+1.38 \mathrm{e}$ as compared to $+1.89 \mathrm{e}$ in the pure oxide. This decrease in positive charge in Ir atoms suggests the presence of $\mathrm{Ir}^{3+}$ (also observed in oxide films $\left.{ }^{21}\right)$. DFT tends to over-delocalize electrons and therefore reflect the covalent nature of metal-ligand bonds in crystals (Ir coordinates to multiple $\mathrm{O}$ atoms) leading to charge-transfer results that temper the formal oxidation state $\left(\mathrm{Ir}^{4+}\right.$ corresponds to $\Delta \mathrm{Q} \sim+1.9$ e and $\mathrm{Ir}^{3+}$ to $\Delta \mathrm{Q} \sim+1.4 \mathrm{e})$. Most excitingly, the thicker $\mathrm{IrO}_{2}$ skin on $\operatorname{Ir}(110)$ features the weakest bound oxygen. The pure surfaces of $\operatorname{Ir}(110)$ and $\mathrm{IrO}_{2}(001)$ typically are thought to over bind oxygen, but an Ir (110) sub-surface with a thicker $\mathrm{IrO}_{2}$ skin binds oxygen less strongly than the metal surface by $1.13 \mathrm{eV}$ and the bulk metal oxide surface by $0.48 \mathrm{eV}$, respectively. The second weakest oxygen adsorption occurs

Table I. Energy Penalty to Crystallinity of Multi-layered $\operatorname{Ir}-\mathrm{IrO}_{2}$ Surface $\left(\Delta \mathrm{E}_{\text {fixed-rel,surf }}\right)$, Adsorption Energy $\left(\mathrm{E}_{\mathrm{O}}\right)$ and Bader Charge $\left(\Delta Q_{0}\right)$ of o.

\begin{tabular}{lllll} 
System & $\Delta \mathrm{E}_{\text {fixed-rel,surf }}(\mathrm{eV})$ & $\mathrm{E}_{\mathrm{O}}(\mathrm{eV})$ & $\Delta \mathrm{Q}_{\mathrm{O}}(\mathrm{e})$ & ${\mathrm{Compared} \mathrm{to} \mathrm{E}_{\mathrm{O}} \text { of IrO}}_{2}(001) / \mathrm{E}_{\mathrm{O}}$ of Ir facet \\
\hline 2-1 IrO \\
4-1 $\mathrm{IrO}_{2}(001) / \mathrm{Ir}(100)$ & 56.40 & -1.53 & -0.79 & weaker/weaker \\
2-1 $\mathrm{IrO}_{2}(001) / \mathrm{Ir}(100)$ & 133.51 & -3.15 & -0.30 & stronger/stronger \\
$4-1 \mathrm{IrO}_{2}(001) / \mathrm{Ir}(110)$ & 118.67 & 0.03 & -0.51 & weaker/weaker \\
2-1 $\mathrm{IrO}_{2}(001) / \mathrm{Ir}(111)$ & 21.96 & -1.20 & -0.51 & weaker/weaker \\
$4-1 \mathrm{IrO}_{2}(001) / \mathrm{Ir}(111)$ & 25.67 & -3.00 & -0.64 & stronger/stronger \\
\end{tabular}



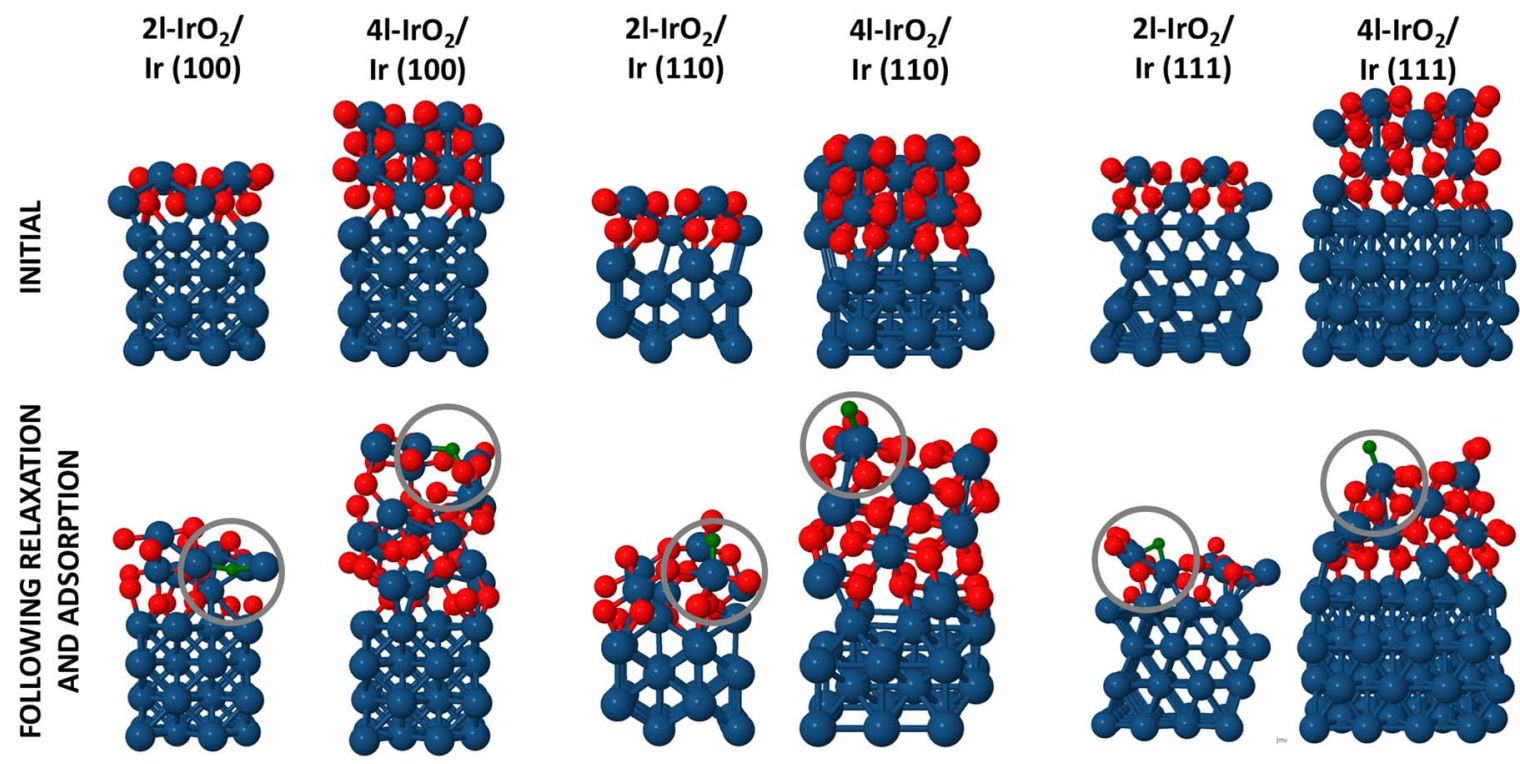
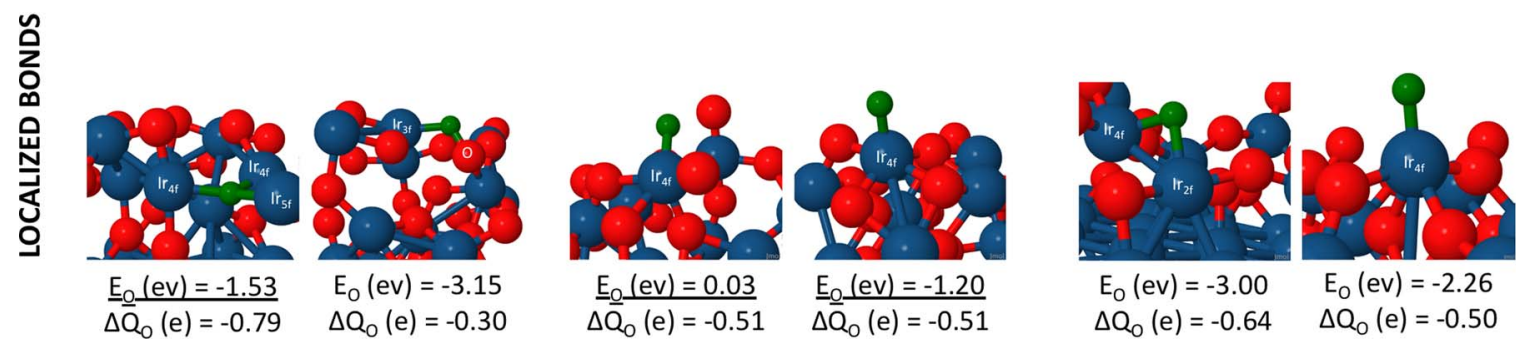

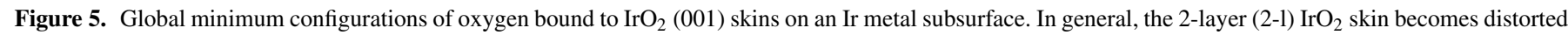

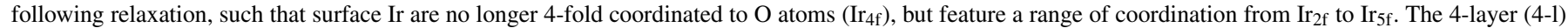

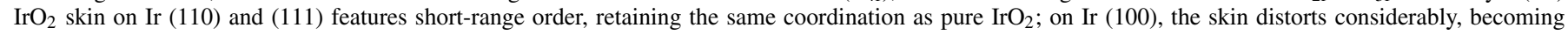

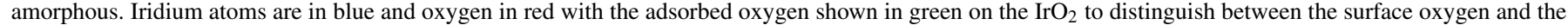
adsorbed oxygen.

on a thin $\mathrm{IrO}_{2}$ skin on $\mathrm{Ir}(100)$ at a hollow site, where Ir atoms are more highly coordinated than on the pure $\mathrm{IrO}_{2}(001)$ surface. The adsorption energy compares similarly to oxygen's adsorption on $\operatorname{Ir}(111)$, also on a hollow site with $\mathrm{E}_{O}$ circa $-1.5 \mathrm{eV}$ (Figure 4). We hypothesize that these shifts may lead to higher activity as weaker oxygen adsorption corresponds to easier desorption of this intermediate, freeing the Ir active site for OER.

In contrast, for cases where the binding strength increases, this may be explained by the changes in coordination of surface Ir atoms $\left(\mathrm{Ir}_{n \mathrm{f}}\right)$ with more under-coordinated $\mathrm{Ir}$ atoms also corresponding to a high degree of amorphousness in the oxide skin. Surface Ir coordination to $\mathrm{O}$ atoms ranges from $\mathrm{Ir}_{2 \mathrm{f}}$, associated with stronger binding, to $\mathrm{Ir}_{5 \mathrm{f}}$, associated with weaker binding. Hence, oxygen adsorption from the thin to thicker skin on Ir (100) results in stronger adsorption with an associating increase in amorphousness, allowing for $\mathrm{O}$ to bind to an $\mathrm{Ir}_{3 \mathrm{f}}$ atom and form an $\mathrm{O}-\mathrm{O}_{\text {surf }}$ single bond of $1.41 \AA$, comparable to the $\mathrm{O}-\mathrm{O}$ bond length in hydrogen peroxide (see SI depicting optimized overlap between the oxygens' $2 p_{x}$ and $2 p_{z}$ orbitals). In contrast, the opposite occurs on Ir (111): the amorphous thin skin becomes more crystalline as it thickens. In both cases, the expanded lattice of the oxide also results in stronger oxygen adsorption in line with previous work, focusing on strained metals. ${ }^{52}$ The oxide skins on Ir (100) and Ir (111) are also relatively porous due to this lattice mismatch: in Ir (100), with the most compression, this results in amorphous under-coordinated Ir-O bonds and in $\operatorname{Ir}(111)$, with the most expansion, the oxide skin expands at the interface of the metal and aggregates at the surface (see SI Tables S.5-S.7 for details). Özer et al. noted that oxidized $\operatorname{Ir}(110)$ featured hydrogen underpotential desorption peaks absent on either pure $\mathrm{IrO}_{2}$ and oxidized $\mathrm{Ir}(111)$, suggesting that this porosity and access to metallic Ir may be advantageous as a bifunctional metal/metal oxide catalyst. ${ }^{37}$ The oxide skin on Ir (110) is less compressed compared to that on Ir (100) and it retains coordination associated with pure $\mathrm{IrO}_{2}$, but with weaker binding of oxygen. We propose that these morphological differences, particularly with the oxide skin on $\operatorname{Ir}(110)$, may explain in part the spike in activity of Ir metal/hydroxide catalysts, at least until oxidation during operation grows a thicker oxide surface corresponding more closely in structure and activity to bulk rutile $\mathrm{IrO}_{2}$. In both our theoretical study and Özer et al.'s single-facet experiments, oxidized $\operatorname{Ir}(110)$ have unique, catalytic features, but cannot explain entirely the increases in OER activity on nanoparticles with multiple Ir facets and correspondingly, different oxide morphologies beyond the calculations done here.

On a fundamental level, however, these calculations of mixed surfaces enrich the discussion of compression/expansion of surfaces corresponding to weaker/stronger adsorption of adsorbates, respectively. ${ }^{40,52}$ While these effects have been observed for metals and their alloys, notably, Pt-M $(\mathrm{M}=\mathrm{Ni}, \mathrm{Co})$ can compress up to $\sim 10 \%$; the interplay between metal and the metal oxides that can grow on them is much less known. ${ }^{33,40}$ Here, we find that the high degree of compression or expansion, due to lattice mismatch between metals and metal oxides, results in much stronger oxygen binding; this can be further clarified by how the oxide skin conforms to the metal subsurface and the change in molecular bonding induced by the resulting structural changes (i.e. the local coordination of adsorption sites). From our computational study, we conclude that the activity differences observed in experiment most likely correspond to morphological changes at the surface altering local bonding 

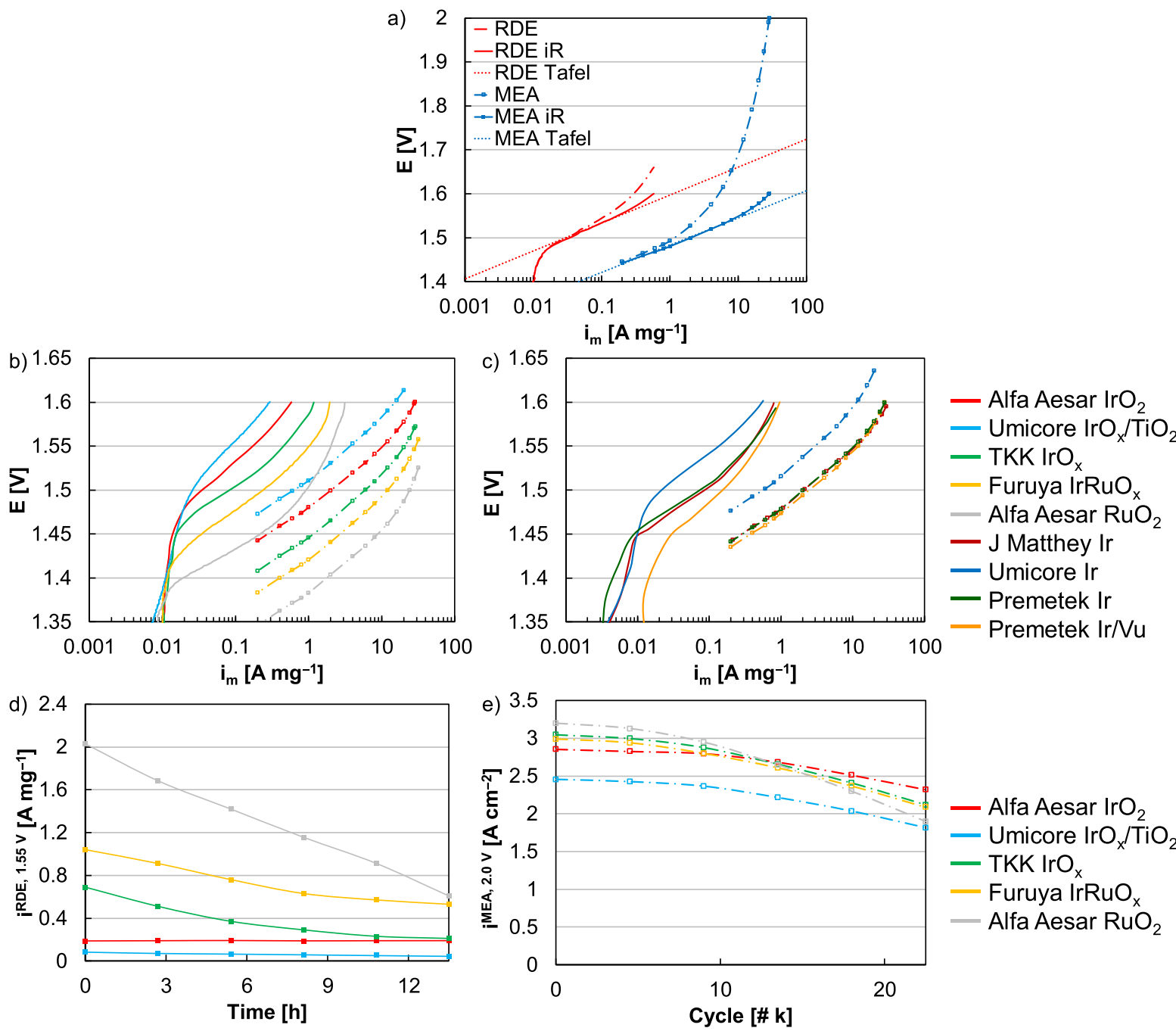

\section{- Alfa Aesar $\mathrm{IrO}_{2}$ - Umicore $\mathrm{IrO}_{\mathrm{x}} / \mathrm{TiO}_{2}$ - TKK IrOx - Furuya IrRuO - Alfa Aesar $\mathrm{RuO}_{2}$}
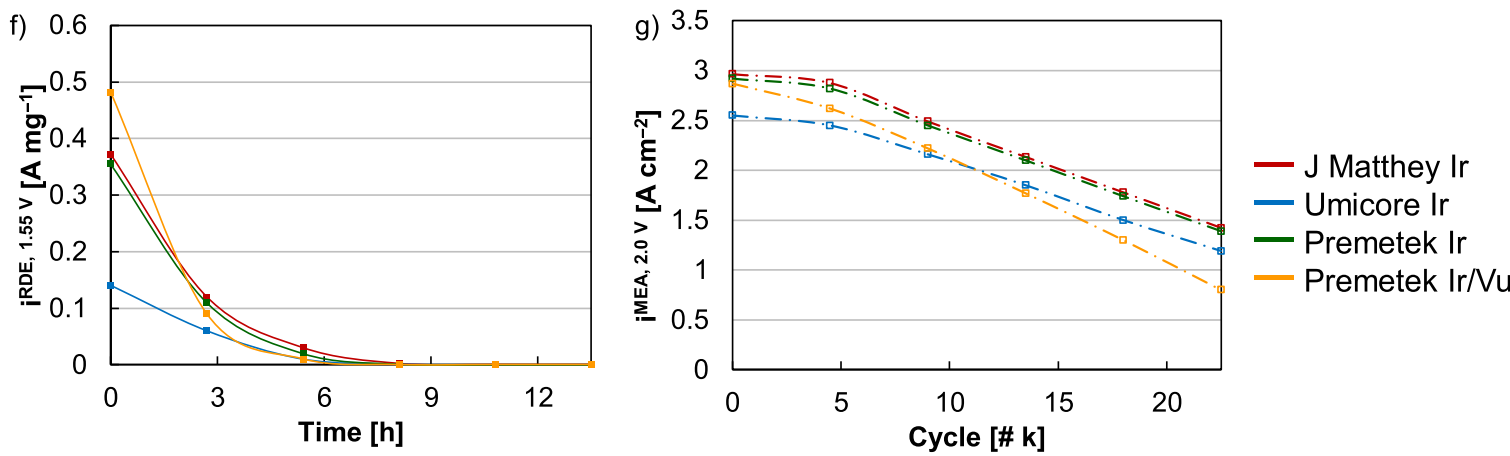

Figure 6. (a) Comparison of Alfa Aesar $\mathrm{IrO}_{2} \mathrm{RDE}$ activity and MEA performance, uncorrected (RDE, MEA), corrected for internal resistance (iR), and corrected for transport (Tafel). Kinetic OER activities of various (b) Ir oxide and (c) Ir (metal/hydroxide) catalysts in RDEs (solid lines) and MEAs (dashed lines). Durability of various (d-e) Ir oxide and (f-g) Ir (metal/hydroxide) catalysts in RDEs (d, f) and MEAs (e, g). RDE activities were determined at $1.55 \mathrm{~V}$ vs. RHE every $2.7 \mathrm{~h}$ during a $13.5 \mathrm{~h}, 2 \mathrm{~V}$ hold. MEA activities were determined at $2 \mathrm{~V}$ and $1.5 \mathrm{~V}$ (kinetics, SI Figure S.17) every $4.5 \mathrm{k}$ cycles during $22.5 \mathrm{k}$ square wave cycles, $30 \mathrm{~s}$ hold at $1.45 \mathrm{~V}$ followed by a $30 \mathrm{~s}$ hold at $2 \mathrm{~V}$. OER activities and performances were corrected for internal resistance, in subfigures (a, where denoted), (b), (c), (d), and (f).

character. Experimentally, in half- and single-cell performance of $\leq$ 1.5 hour, activity and surfaces resemble oxide skins on Ir facets; by the 13.5 hour mark, the activity and surfaces correspond to bulk iridium oxide.

Correlating $R D E$ and $M E A$ performance and durability.-In addition to activity determinations, differences were observed in the durability of $\mathrm{Ir}$ (metal/hydroxide) relative to Ir oxide in RDEs and MEAs. At elevated potential $(2 \mathrm{~V})$ and over a short period of time $(13.5 \mathrm{~h})$ in RDE, Ir oxide lost no activity while Ir lost all activity. In MEAs, however, durability differences were smaller and took extended operation (weeks) to realize. To assess how well RDE activity and durability correlates to MEA testing, a variety of catalysts were evaluated, including materials with different surface 
compositions (metals/oxides), supports (titania, carbon), morphologies/ECAs, and components (Ru). While RDE/MEA comparisons are inherently challenging, several trends were observed.

RDEs kinetically underperformed MEAs by at least an order of magnitude, which may be due to differences in temperature, interface (membrane/supporting electrolyte), and electrode alignment (Figure 6a). Bridging that gap requires increasing RDE temperature or improving reactant access (from convection to forced flow). Although RDE/MEA performance did not match quantitatively, activity trends in RDE translated to the kinetic region of MEAs (Figures 6b, 6c, SI Figure S.16). Making these comparisons required segregating catalysts based on oxide content into oxide (Figure $6 \mathrm{~b}$, rutile or mixed oxides with no hydrogen underpotential features) and metal (Figure 6c, metal or hydroxide with hydrogen underpotential features) groups. Correlating RDE/MEA performance also relied on extended RDE conditioning protocols (100 cycles, 1.2-1.8 V); in cases, fewer cycles to more moderate potentials created activity differences that did not match MEAs and may affect RDE assessments in literature. Extended RDE conditioning may have negated differences in crystallinity and surface faceting by exposure to elevated potential, resulting in reordering of catalyst surfaces. While differences in surface structure may produce large activity differences in RDE following no or minimal conditioning, they did not appear to affect MEA performance and MEA conditioning protocols may similarly reorder crystalline/amorphous surfaces or preferentially exposed facets. For oxides (Figure 6b), Umicore $\mathrm{IrO}_{\mathrm{x}}$ /titania, TKK $\mathrm{IrO}_{\mathrm{x}}$, Furuya $\operatorname{IrRuO}_{\mathrm{x}}$, and Alfa Aesar $\mathrm{RuO}_{2}$ produced 0.4, 2.5, 5.6, and 10.9 times the activity of Alfa Aesar $\mathrm{IrO}_{2}$, respectively in RDE; similar differences $(0.3,2.1,5.2,11.0$ times the activity) were found in MEA kinetics. For the mixed oxides $\left(\right.$ Umicore $\mathrm{IrO}_{\mathrm{x}} /$ titania, $\mathrm{TKK} \mathrm{IrO}_{\mathrm{x}}$, Furuya $\mathrm{IrRuO}_{\mathrm{x}}$ ), a fractionally lower than expected MEA performance was found and may have been due to incomplete oxidation and oxide growth in RDEs. For metals (Figure 6c), Umicore Ir, Premetek Ir, and Premetek Ir/Vulcan produced $0.4,1.0$, and 1.3 times the activity of Johnson Matthey Ir, respectively in RDE; similar differences (0.4, 1.0, 1.1 times the activity) were found in MEA kinetics. For the supported catalyst (Premetek Ir/Vulcan), a lower than expected MEA performance was found and may have been due to carbon corrosion during conditioning.

Significant differences were also observed between catalyst durability in RDEs and MEAs. For metals, complete loss in RDE occurred for all catalysts within $5.4 \mathrm{~h}$ ( $2 \mathrm{~V}$ hold, Figure $6 \mathrm{~d})$. Ir metal losses in MEAs, however, were less severe than in RDE and over longer periods of time ( $>2 \mathrm{wk}$ ). For the oxides (rutile, mixed oxides), higher durability than metals were observed in both RDEs and MEAs (Figure 6c). For example, Ir oxide (rutile) lost no activity in RDE $(2 \mathrm{~V}, 13.5 \mathrm{~h})$ and $19 \%$ performance after $22.5 \mathrm{k}$ cycles in MEAs (compared to $52 \%$ for $\mathrm{Ir}$ metal). Larger losses were observed in two instances. The mixed oxides (Umicore $\mathrm{IrO}_{\mathrm{x}} /$ titania $26 \%$, TKK $\mathrm{IrO}_{\mathrm{x}} 30 \%$, Furuya $\mathrm{IrRuO}_{\mathrm{x}} 34 \%$ ) were less durable than rutile Ir and the degree of oxidation and resulting dissolution rate may have impacted durability (SI Table S.2); and as expected, Ru-containing catalysts (Furuya $\mathrm{IrRuO}_{\mathrm{x}} 34 \%$, Alfa Aesar $\mathrm{RuO}_{2} 41 \%$ ) were less durable than $\mathrm{Ir}^{4}$ In addition to these factors, increased morphology/ECA may play a role and could have impacted the $\mathrm{TKK}_{\mathrm{IrO}}$ durability by increasing the site quantity and dissolution rate (SI Table S.2).

In terms of performance, activity differences in RDE correlated to differences in MEA kinetics for various material sets, including supports, morphologies, and components. Standard half-cell test protocols, however, appeared unable to account for differences in surface oxidation and exaggerated metal/hydroxide activity relative to rutile in single-cells. RDE may also be reasonable for comparing the relative durability of catalysts and assessing whether materials are ready for MEA implementation. While low RDE loading may accelerate loss observations, however, the approach appeared unable to accelerate a continual operation loss mechanism or predict device lifetime. The catalyst oxide content is therefore a necessary consideration when evaluating performance and durability that impacts how comparisons are made and how device improvements can be realized.

\section{Conclusions}

In this study, PW-DFT was combined with RDE and MEA testing to understand the activity differences between Ir surfaces and how these differences affect electrolysis performance. For Ir metal/hydroxide, oxide skins at the surface may weaken O-binding, improving activity relative to rutile Ir oxide. A variety of catalyst types appeared to improved kinetics and activity improvements in RDE generally correlated to MEA testing. Activity differences between Ir (metal/hydroxide) and Ir oxide surfaces in RDEs, however, only translated to MEAs when avoiding typical operating conditions (conditioning, elevated temperature), and in cases, RDE could exaggerate the performance of metal/hydroxide surfaces due to common differences in test protocols. While stabilized Ir (metal/hydroxide) surfaces could potentially improve electrolyzer kinetics by preventing oxidation, it is unclear if catalyst development efforts can delay/suppress oxidation without adversely impacting intermediate binding and OER activity, or whether stabilization could be effective given the time, temperature, and potential requirements of electrolyzers. In durability, RDE accelerated loss observation with low loading but could not reasonably accelerate the relevant loss mechanisms from continuous or intermittent operation. While durability differences for various catalyst types qualitatively correlated between RDE and MEA testing, RDEs produced much higher losses for metals/hydroxides than observed in MEAs. Differences between RDE and MEA activity/durability demonstrate the need for caution when using ex-situ tests to predict in-situ performance and lifetime. While RDE activity improvements can translate to MEA kinetics, accounting for surface species appears critical since RDE can overestimate the activity and underestimate the durability of Ir relative to Ir oxide in MEAs.

Fundamentally, oxide skins at metal surfaces can exhibit unique morphological features, including different coordination, compression or expansion related to lattice mismatch, and weaker or stronger binding relative to the pure metal or metal oxide. Metal passivation and oxide growth significantly influences adsorption and activity in catalysis, and, specifically, oxide skins grown on Ir (110) may explain the increased activity present initially in half-cell and singlecell electrolysis. Beyond the specific systems and applications studied here, passivated metal surfaces are of broad interest to other technologies since the sub-surface facet can considerably influence the oxide skin's physicochemical properties. This includes applications involving: energy conversion such as other electrolyzer types (anion exchange membrane, high temperature, photoelectrochemical); fuel cells; batteries; the electrochemical synthesis of ammonia, polymers, and fuels (carbon dioxide reduction); processes such as corrosion and plating; sensors; and electron- and ion-transport for electrochromic properties in displays or p-n junctions in electrical devices (transistors, photovoltaics). Therefore, a careful consideration of how passivated metal surfaces form and change for each application is needed to understand both device lifetimes and ultimate performance limitations under operating conditions.

\section{Acknowledgments}

This work was supported by the Laboratory Directed Research Development program at the National Renewable Energy Laboratory (NREL). M.-A. H. was funded via the NREL's Director's Fellowship. This work was authored by the National Renewable Energy Laboratory, operated by Alliance for Sustainable Energy, LLC, for the U.S. Department of Energy (DOE) under Contract No. DE-AC3608GO28308. Funding provided by U.S. Department of Energy Office of Energy Efficiency and Renewable Energy Fuel Cell Technologies Office. The views expressed in the article do not necessarily represent the views of the DOE or the U.S. Government. The U.S. Government retains and the publisher, by accepting the article for publication, acknowledges that the U.S. Government retains a nonexclusive, paid-up, irrevocable, worldwide license to publish or reproduce the published 
form of this work, or allow others to do so, for U.S. Government purposes.

\section{ORCID}

Shaun M. Alia (1) https://orcid.org/0000-0002-7647-9383

Svitlana Pylypenko (D) https://orcid.org/0000-0001-7982-734X

\section{References}

1. B. Pivovar, N. Rustagi, and S. Satyapal, The Electrochemical Society Interface, 27, 47 (2018).

2. K. E. Ayers, J. N. Renner, N. Danilovic, J. X. Wang, Y. Zhang, R. Maric, and H. Yu, Catal. Today, 262, 121 (2016)

3. S. M. Alia, B. Rasimick, C. Ngo, K. C. Neyerlin, S. S. Kocha, S. Pylypenko, H. Xu, and B. S. Pivovar, J. Electrochem. Soc., 163, F3105 (2016).

4. M. Pourbaix, Atlas of electrochemical equilibria in aqueous solutions, National Association of Corrosion Engineers, Houston, Texas (1974).

5. N. Danilovic, R. Subbaraman, K.-C. Chang, S. H. Chang, Y. J. Kang, J. Snyder A. P. Paulikas, D. Strmenik, Y.-T. Kim, and D. Myers, The Journal of Physical Chemistry Letters, 5, 2474 (2014).

6. T. Reier, M. Oezaslan, and P. Strasser, ACS Catalysis, 2, 1765 (2012).

7. S. M. Alia and G. C. Anderson, J. Electrochem. Soc., 166, F282 (2019).

8. V. Pfeifer, T. E. Jones, J. J. V. Vélez, R. Arrigo, S. Piccinin, M. Hävecker A. Knop-Gericke, and R. J. C. S. Schlögl, Chem. Sci., 8, 2143 (2017).

9. T. Li, O. Kasian, S. Cherevko, S. Zhang, S. Geiger, C. Scheu, P. Felfer, D. Raabe, B. Gault, and K. J. J. Mayrhofer, Nat. Catal., 1, 300 (2018).

10. C. Wang, R. B. Moghaddam, and S. H. Bergens, The Journal of Physical Chemistry $C, \mathbf{1 2 1}, 5480$ (2017)

11. R. B. Moghaddam, C. Wang, J. B. Sorge, M. J. Brett, and S. H. Bergens, Electrochem. Commun., 60, 109 (2015).

12. T. Reier, Z. Pawolek, S. Cherevko, M. Bruns, T. Jones, D. Teschner, S. r. Selve, A. Bergmann, H. N. Nong, and R. Schlögl, JACS, 137, 13031 (2015).

13. H. N. Nong, L. Gan, E. Willinger, D. Teschner, and P. Strasser, Chemical Science, 5 , 2955 (2014).

14. H. N. Nong, H. S. Oh, T. Reier, E. Willinger, M. G. Willinger, V. Petkov, D. Teschner, and P. Strasser, Angew. Chem. Int. Ed., 54, 2975 (2015).

15. W. Sun, Y. Song, X.-Q. Gong, L.-M. Cao, and J. Yang, Chemical Science, 6, 4993 (2015).

16. F. Godínez-Salomón, L. Albiter, S. M. Alia, B. S. Pivovar, L. E. Camacho-Forero, P. B. Balbuena, R. Mendoza-Cruz, M. J. Arellano-Jimenez, and C. P. Rhodes, ACS Catalysis, 8, 10498 (2018).

17. S. M. Alia, S. Shulda, C. Ngo, S. Pylypenko, and B. S. Pivovar, ACS Catalysis, 8 , 2111 (2018).

18. H. Xu, High-Performance, Long-Lifetime Catalysts for Proton Exchange Membrane Electrolysis, http://www.hydrogen.energy.gov/pdfs/review15/pd103_xu_ 2015_o.pdf (2015).

19. J. Schoiswohl, M. Sock, Q. Chen, G. Thornton, G. Kresse, M. Ramsey, S. Surnev, and F. Netzer, Top. Catal., 46, 137 (2007).
20. S. Surnev, A. Fortunelli, and F. P. Netzer, Chem. Rev, 113, 4314 (2012).

21. J. McIntyre, W. Peck, and S. Nakahara, J. Electrochem. Soc., 127, 1264 (1980).

22. S. Hackwood, A. Dayem, and G. Beni, Phys. Rev. B, 26, 471 (1982).

23. M. Shipilin, E. Lundgren, J. Gustafson, C. Zhang, F. Bertram, C. Nicklin, C. J. Heard, H. Grönbeck, F. Zhang, and J. Choi, Top. Catal., 60, 492 (2017).

24. W. Kudernatsch, G. Peng, H. Zeuthen, Y. Bai, L. R. Merte, L. Lammich, F. Besenbacher, M. Mavrikakis, and S. Wendt, ACS Nano, 9, 7804 (2015).

25. X. Xu, Q. Fu, X. Guo, and X. Bao, ACS Cat., 3, 1810 (2013).

26. J. A. Rodriguez, P. Liu, D. J. Stacchiola, S. D. Senanayake, M. G. White, and J. G. Chen, ACS Cat., 5, 6696 (2015).

27. B. von Boehn and R. Imbihl, J. Phys. Chem. C, 122, 12694 (2018).

28. S. M. Alia, K. E. Hurst, S. S. Kocha, and B. S. Pivovar, J. Electrochem. Soc., 163, F3051 (2016).

29. S. P. Kounaves and J. Buffle, J. Electrochem. Soc., 133, 2495 (1986).

30. G. Kresse and J. Furthmüller, Comput. Mater. Sci., 6, 15 (1996).

31. G. Kresse and D. Joubert, Phys. Rev. B, 59, 1758 (1999).

32. J. P. Perdew, A. Ruzsinszky, G. I. Csonka, O. A. Vydrov, G. E. Scuseria, L. A. Constantin, X. Zhou, and K. Burke, Phys. Rev. Lett., 100, 136406 (2008).

33. R. W. G. Wyckoff, Crystal Structures, Wiley (1963)

34. G. Henkelman, A. Arnaldsson, and H. Jónsson, Comput. Mater. Sci., 36, 354 (2006).

35. R. Hoffmann, Rev. Mod. Phys., 60, 601 (1988)

36. S. M. Alia, H2@ Scale: Experimental Characterization of Durability of Advanced ElectrolyzerConcepts in Dynamic Loading, https://www.hydrogen.energy.gov/pdfs/ review18/tv146_alia_2018_p.pdf (2018).

37. E. Özer, C. Spöri, T. Reier, and P. J. C. Strasser, ChemCatChem, 9, 597 (2017).

38. T. H. Yu, T. Hofmann, Y. Sha, B. V. Merinov, D. J. Myers, C. Heske, and W. A. Goddard III, The Journal of Physical Chemistry C, 117, 26598 (2013).

39. J. K. Nørskov, J. Rossmeisl, A. Logadottir, L. Lindqvist, J. R. Kitchin, T. Bligaard, and H. Jonsson, The Journal of Physical Chemistry B, 108, 17886 (2004).

40. S. M. Alia, C. Ngo, S. Shulda, M.-A. Ha, A. A. Dameron, J. N. Weker, K. C. Neyerlin, S. S. Kocha, S. Pylypenko, and B. S. Pivovar, ACS Omega, 2, 1408 (2017).

41. Y. He, A. Stierle, W. Li, A. Farkas, N. Kasper, and H. Over, J. Phys. Chem. C, 112, 11946 (2008).

42. A. Serventi, M. El Khakani, R. Saint-Jacques, and D. Rickerby, J. Mater. Res., 16, 2336 (2001).

43. R.-S. Chen, A. Korotcov, Y.-S. Huang, and D.-S. Tsai, Nanotechnology, 17, R67 (2006).

44. F. Sen, A. Kinaci, B. Narayanan, S. Gray, M. Davis, S. Sankaranarayanan, and M. Chan, J. Mater. Chem. A, 3, 18970 (2015)

45. O. Matz and M. Calatayud, J. Phys. Chem. C, 121, 13135 (2017).

46. W.-H. Chung, D.-S. Tsai, L.-J. Fan, Y.-W. Yang, and Y.-S. Huang, Surf. Sci., 606, 1965 (2012)

47. Y. Sun, B. Mayers, T. Herricks, and Y. Xia, Nano Lett., 3, 955 (2003).

48. S.-H. Zhang, Z.-Y. Jiang, Z.-X. Xie, X. Xu, R.-B. Huang, and L.-S. Zheng, J. Phys. Chem. B, 109, 9416 (2005).

49. N. M. Marković, R. R. Adžić, B. D. Cahan, and E. B. Yeager, J. Electroanal. Chem., 377, 249 (1994)

50. R. Rai, T. Li, Z. Liang, M. Kim, A. Asthagiri, and J. F. Weaver, Surf. Sci., 652, 213 (2016).

51. Z. Zeng, K.-C. Chang, J. Kubal, N. M. Markovic, and J. Greeley, Nat. Energy, 2, 17070 (2017).

52. M. Mavrikakis, B. Hammer, and J. K. Nørskov, Phys. Rev. Lett., 81, 2819 (1998). 